Research Article

\title{
Hydroforming Process for an Ultrasmall Bending Radius Elbow
}

\author{
Shangwen Ruan $\mathbb{D}^{1}{ }^{1}$ Lihui Lang, ${ }^{1}$ and Yulong $\mathrm{Ge}^{2}$ \\ ${ }^{1}$ School of Mechanical Engineering and Automation, Beihang University, Beijing, China \\ ${ }^{2}$ State Key Laboratory of Automotive Safety and Energy, Department of Automotive Engineering, Tsinghua University, \\ Beijing, China \\ Correspondence should be addressed to Shangwen Ruan; ruanshangwen@buaa.edu.cn
}

Received 1 November 2017; Revised 9 January 2018; Accepted 12 February 2018; Published 1 April 2018

Academic Editor: Giovanni Berselli

Copyright (c) 2018 Shangwen Ruan et al. This is an open access article distributed under the Creative Commons Attribution License, which permits unrestricted use, distribution, and reproduction in any medium, provided the original work is properly cited.

\begin{abstract}
Bent pipes are widely used in automotive, aviation, and aerospace industries for delivering fluids. Parts having small relative bending radiuses are called elbows. However, fabricating a thin-walled elbow part using the simple bending process poses many challenges. One possible way to manufacture elbows is with the stamping-welding process. The major drawbacks of this method include the decline in sealing performance and the addition in weight attributed to the lap welding process. Tube hydroforming (THF) is considered as a feasible solution to these problems. However, the forming process could be quite complex, and multistep forming is necessary. This study investigates the effects of preliminary processes on elbow forming such as bending, partition forming, and heat treatment and presents a high-performance optimized process design to achieve an ultrasmall radius elbow. The effects of multistep forming on the thickness distribution and the heat treatment on the microstructure have been evaluated. The results obtained from simulations show a reasonable agreement with those from the experiments.
\end{abstract}

\section{Introduction}

With an increasing demand on lightweight products, many thin-walled hollow structural parts have been widely applied in the fields of transport instead of casted ones. Bent pipes and elbows are common components found in piping systems for their flexibility compared to straight pipes [1]. Tube NC bending is the major process to manufacture bent pipes, but it is too hard to obtain an elbow with relative bending radius less than 1.0 with this method [2], even with local heating [3]. The stamping-welding process can be used as an option in industry [4]. Similarly, the use of flanges is unavoidable in the lap welding process, which adds excessive weight to components and introduces the risk of fluid leakage.

Tube hydroforming (THF) technology is attracting much attention as a superior option to traditional manufacturing methods. The so-called bending-bulging forming is very appropriate to form elbow parts [5]. The blank can be either a seamless tube or a brazed tube. High hydraulic pressure and axial feeding are applied to the internal wall of the tube to force the blank to attach the die cavity. To obtain an elbow part without failure, thickness, stress, and strain distributions through steps should be evaluated. Furthermore, the process design, which includes sequence and parameters such as feeds and forming pressure, should be optimized. Bending, hydroforming, and heat treatment combinations have been employed to achieve the bending-bulging, and their influences on the component quality have been investigated. Yuan et al. [6] put forth a hydroforming process for the manufacturing of large elbow pipes based on integral hydrobulging forming technology of spherical and ellipsoidal shells. In this process, a toroidal component with a polygonal cross section prewelded by sheets is filled with a liquid medium and then pressurized by a pump. It can be cut into four $90^{\circ}$ elbows so that a large diameter elbow pipe can be manufactured without special equipment or dies. However, assembling and welding are required. Shr [7] reviewed and analyzed the bending process for hydroforming and gave an understanding of the relationship between design parameters and bending characteristics. Kong et al. [8] studied the 


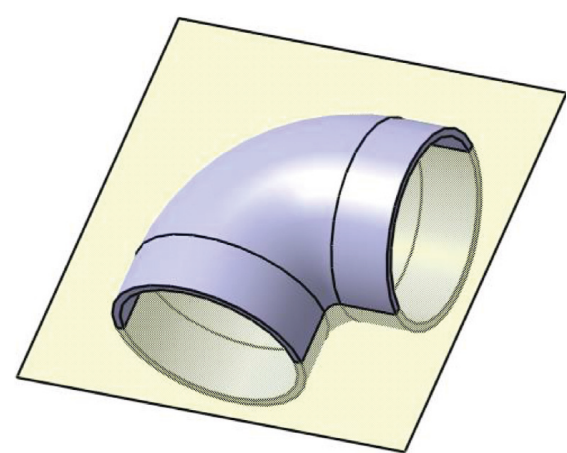

(a)

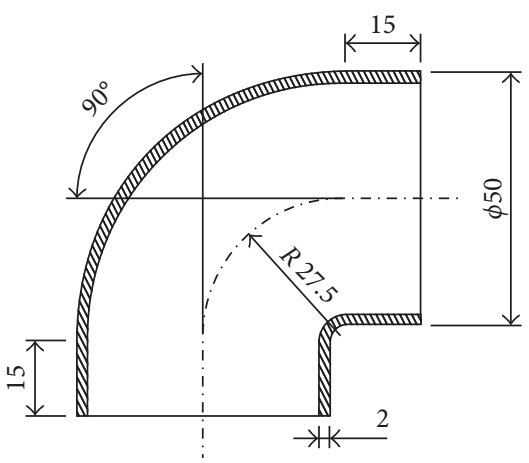

(b)

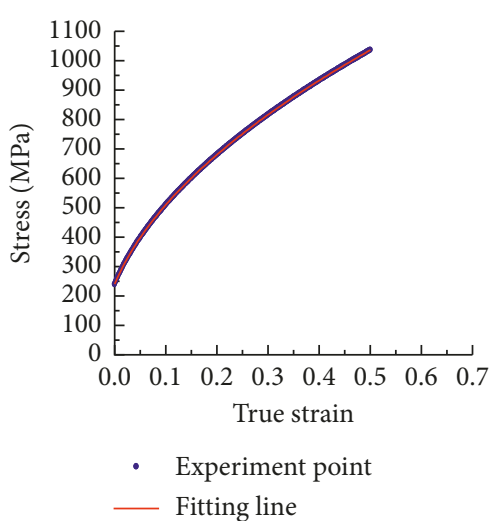

(c)

Figure 1: Model of the targeted component and material. (a) Isometric view, (b) sectional view, and (c) material harden law.

deformation behavior and the failure in bending-bulging forming. This study showed that the bending operation might consume most of the formability of the tube, the fracture failure sometimes occurred outside of the bending, and the maximum work hardening effect takes place around the rear end of the bend section. Thanakijkasem et al. [9] considered effects of bright annealing in the tube hydroforming process. For 304 stainless steel, during the forming deformation, the induced martensitic transformation takes place at the deformed area in an anisotropic way, leading to the development of texture and working hardening. It is found that, at the temperature of $1050^{\circ} \mathrm{C}$, holding for $30 \mathrm{~min}$, and rapidly cooling by purging nitrogen gas, best tensile test results were achieved. Ma et al. [10] carried out the effect of processes on tube hydroforming and achieved a sound complex 3D pipe. The results showed that considerable thickness variations and phase transformation at the curve zones after the bending process were present. Heat treatment must be provided to improve the formability of the tube. On the other hand, considering the process parameters, An et al. [11] and Ge et al. [12] used a multiobjective optimization algorithm to achieve better loading path solutions for bending-bulging processes separately.

Although previous studies have given examples of bending-bulging processes, obtaining a well-performance elbow part is still difficult in several aspects, including the effects of welding, risk of defection, and massive computing. In this paper, the component under consideration is an ultrasmall bending radius elbow made of 304 stainless steel. The preliminary processes are investigated using both numerical and experimental methods. The simulations are implemented using LS-DYNA software.

\section{Part Description}

2.1. Part Specifications. In the present study, the manufacture of an ultrasmall bending radius elbow used in an automobile engine was studied. The model of this component is depicted in Figure 1. The desired outer diameter $D$ is $50.0 \mathrm{~mm}$ and the bending radius $R$ is $27.5 \mathrm{~mm}$, respectively. Thus, the relative bending radius $R / D$ is about 0.56 , which is very small in comparison to the commonly observed value of 0.8 . The initial thickness of the blank is $2.0 \mathrm{~mm}$ and the permissible thinning ratio is $30 \%$, which means that the minimum allowable thickness of the part must be larger than $1.4 \mathrm{~mm}$. The material of this part is 304 austenitic stainless steel manufactured by BAOSTEEL. Young's modulus and Poisson's ratio are $207 \mathrm{GPa}$ and 0.28 , respectively. The stress $(\sigma)$-strain $(\varepsilon)$ relationship can be represented in the Swift harden law as follows:

$$
\begin{aligned}
\sigma & =K \cdot(\bar{\varepsilon}+\varepsilon)^{n} \\
& =1426.5 \times(0.029+\varepsilon)^{0.5},
\end{aligned}
$$

where $K$ is the strength coefficient, $\bar{\varepsilon}$ is the initial strain, and $n$ is the harden exponent.

2.2. Part Analysis. Considering the required part shape, the tube initially needs to be bent. During the bending process, the inside of the bend is thickened by the tensioncompression stress and the outside is thinned due to the tension-tension stress, which can be seen in Figure 2.

The thicknesses of outside $t_{\mathrm{o}}$ and inside $t_{\mathrm{i}}$ of bending can be evaluated using the following equation [7]:

$$
\begin{aligned}
& t_{\mathrm{o}}=\frac{2 R}{2 R+D_{0}-t_{0}} t_{0}=\left(1-\frac{1-t_{0} / D_{0}}{2 R / D_{0}+1-t_{0} / D_{0}}\right) t_{0}, \\
& t_{\mathrm{i}}=\frac{2 R / D_{0}}{2 R / D_{0}-1+t_{0} / D_{0}} t_{0}=\left(1+\frac{1-t_{0} / D_{0}}{2 R / D_{0}-1+t_{0} / D_{0}}\right) t_{0},
\end{aligned}
$$

where $D_{0}$ and $t_{0}$ represent the initial outer diameter and thickness, respectively, and $R$ is the bending radius. When the thickening and thinning are inaptly controlled, the instability of the material may lead to defects including wrinkles and cracks in the tube. According to the geometry relationships of bending, the limited bending radius $R / D_{0}$ (LBR) must be satisfied. LBR describes an extreme condition, where the elongation on the outside reaches the tension fracture strain of the material. At this point, the relationship of the outer diameter must satisfy the following constraint [7]: 

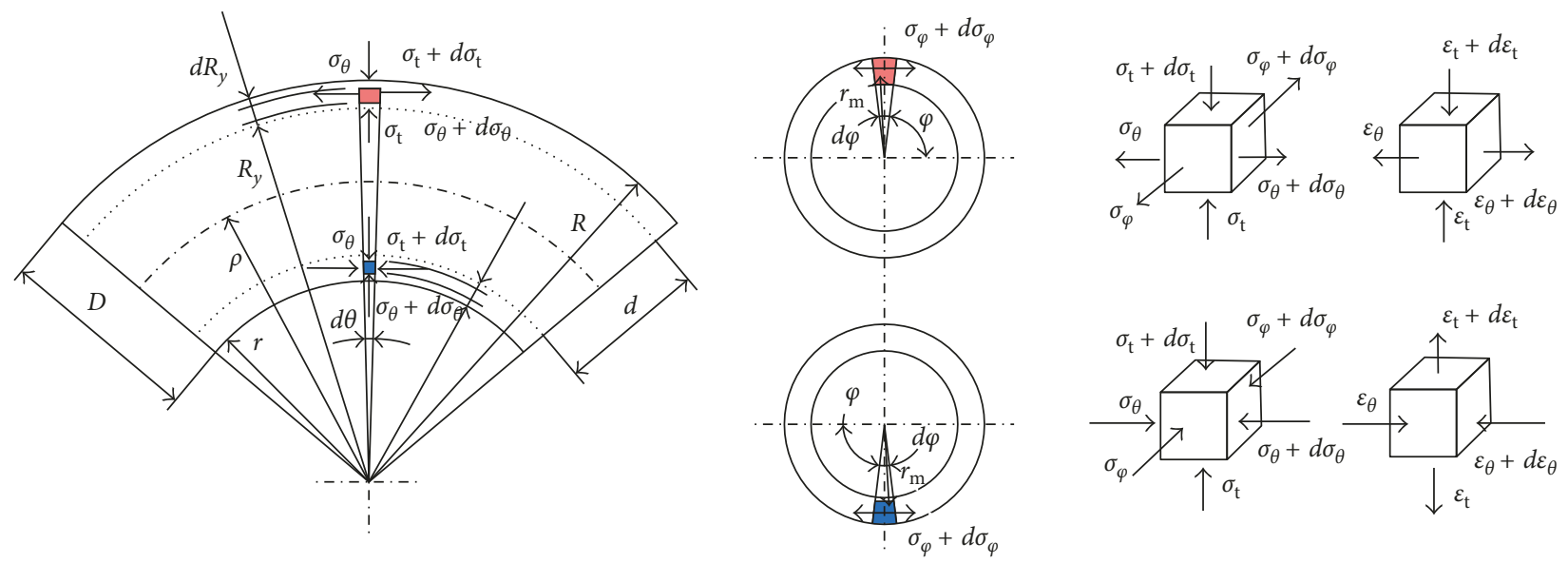

FIGURE 2: Stress and strain state of the bending process.

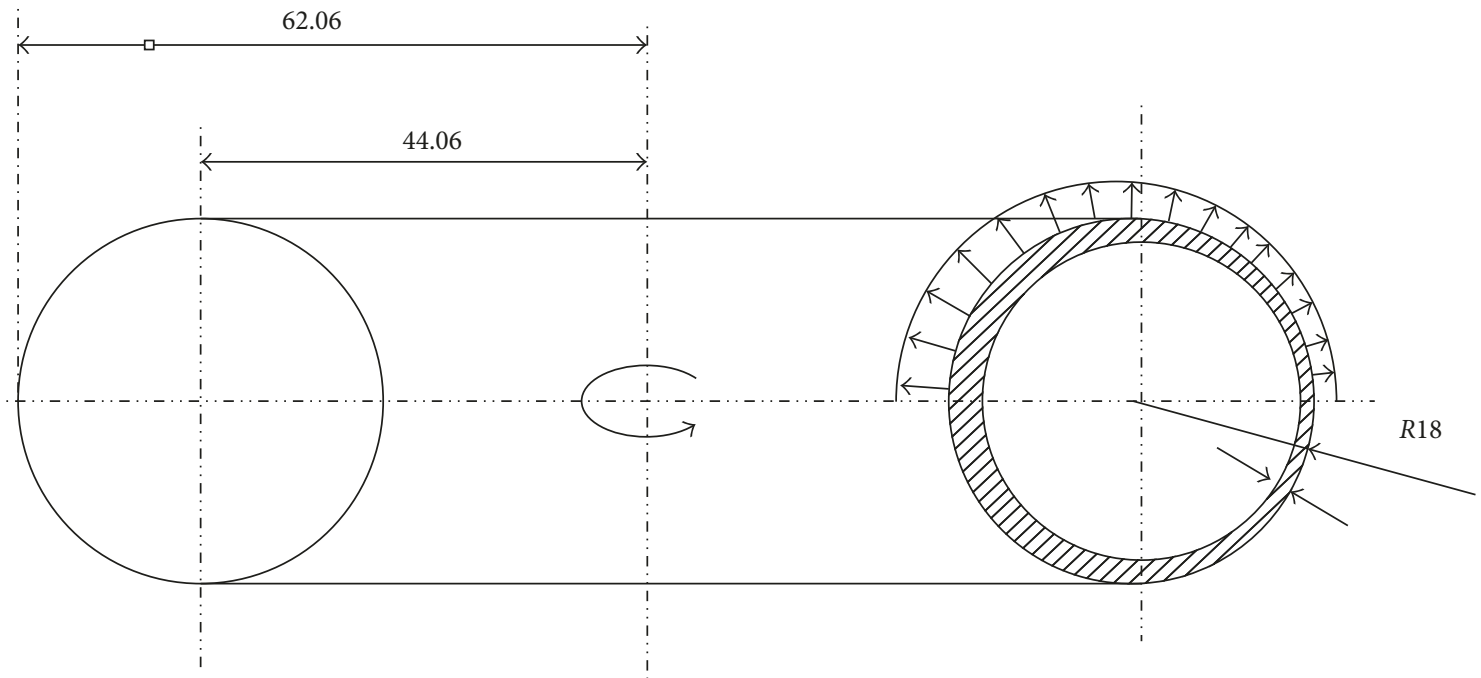

Figure 3: Torus model analysis under internal pressure.

$$
\frac{R}{D_{0}}>\frac{1}{2\left(e^{\varepsilon_{f}}-1\right)}
$$

where $\varepsilon_{\mathrm{f}}$ is the fracture strain. The actual $R$ should be much larger than the minimum value. In practice, the limited relative bending radius is about 1.5. Thus, it is too hard to obtain an elbow component only using the bending process. The bent tube must be bulged up to satisfy the requirement shape with a very high expansion ratio $\eta$, which may result in overthinning of the material in the forming process. The expansion ratio can be expressed as [13]

$$
\eta=\frac{D}{D_{0}},
$$

where $D$ is the maximum section diameter.

Compared to the bulging process of the straight tube, the bending-bulging process is much more complicated. A simplified torus model has been used to analyze this process. In a torus model, the homogeneous internal pressure $p$ is placed on the inner surface as illustrated in Figure 3.
According to the equilibrium equations, the axial stress $\sigma_{\theta}$ and the hoop stress $\sigma_{\varphi}$ can be expressed as [8]

$$
\begin{aligned}
& \sigma_{\theta}=\frac{p D}{4 t}\left(2-\frac{\sin \varphi}{2 R / D-\sin \varphi}\right), \\
& \sigma_{\varphi}=\frac{p D}{4 t},
\end{aligned}
$$

where $\varphi$ is the angle between the bending line and the section normal direction and $t$ is the current thickness. From (6), it can be found that the stress distributes uniformly along the hoop direction, and from (5), the ratio of axial and hoop stress $\sigma_{\theta} / \sigma_{\varphi}$ would be very high when the relative bending radius is small. Meanwhile, the axial stress on the inside of bending could be much larger than the one on the outside, potentially resulting in serious problems in elbow forming explained as follows.

In the elbow-forming process, however, the boundary conditions of bending-bulging are quite different to the 


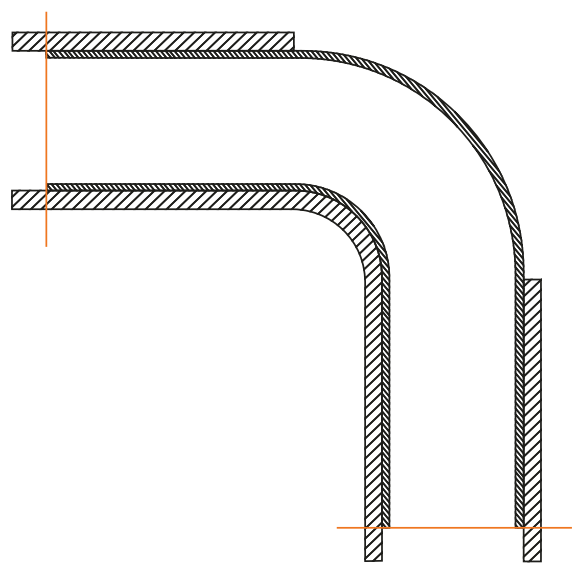

(a)

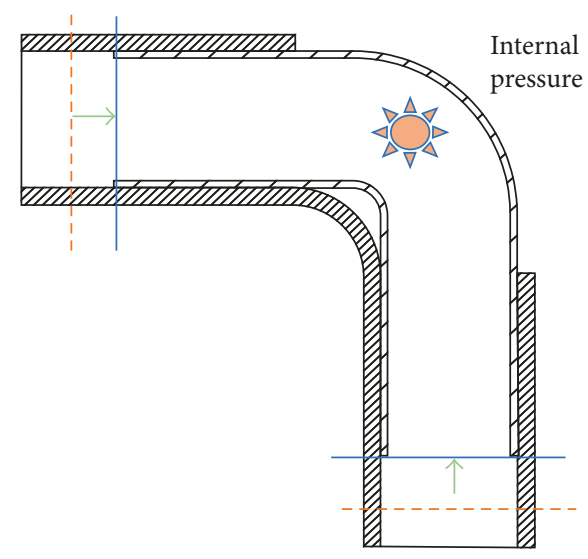

(b)

Figure 4: Movement of the bent tube under internal pressure: (a) bent tube and (b) pressure imposed.

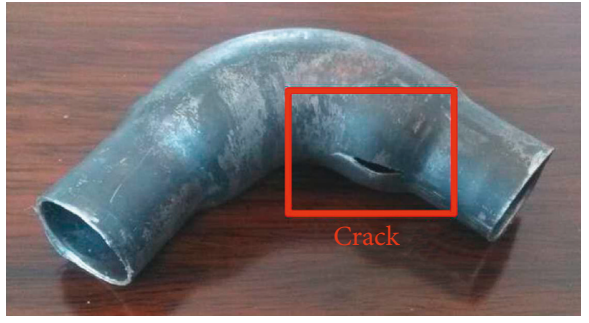

(a)

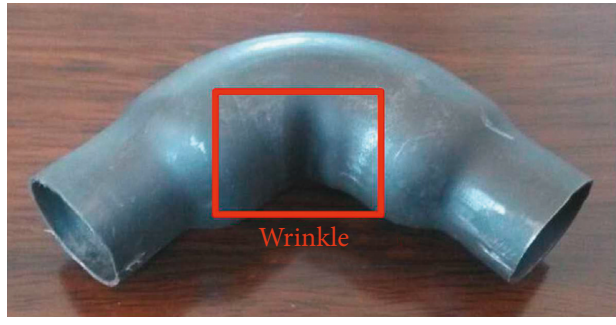

(b)

Figure 5: Defections in the forming process: (a) crack and (b) wrinkle.

quarter symmetry section of a torus. Since the ends of an elbow are not fixed and potential axial feedings in the hydroforming process, they are not capable of offering the axial tension forces on the cross section. The axial stresses on the tube ends will be zero, or for most cases, they will be negative. So, the equilibrium equation (5) in the torus model along axial direction cannot be matched in the elbowforming process. As a result, when the internal pressure is imposed on the tube, because of a larger area, the force on the outside bend is higher than that on the inside and there is an unbalanced condition. It will make the tube deviate from the bending center to outward until it reaches the die surface, as detailed in Figure 4. Here, due to the thickness changing on the tube, the hoop stress distribution is no longer uniform. The thickened area is less likely to further deform. This may cause overthinning in bulging, as shown in Figure 5(a).

On the other hand, there is a tendency for the tube ends to shrink, especially on the inside. For this reason, axial feeding of the material to the bulging zone is very difficult to achieve because the wrinkle or buckle cannot be flattened. A large expansion ratio is difficult to realize, as seen in Figure 5(b).

To summarize, the major challenges for a small relative bending radius elbow-forming process are the following: (a) small relative bending radius is hard to obtain using bending itself, (b) the inner pressure loading could lead to a wrinkle on the inside of the bend, and (c) inhomogeneous thickness distribution could aggravate the wrinkle and also result in crack on thinning areas.
However, if the process is well designed, the characteristic of the bent tube can be helpful to obtaining a qualified elbow component.

\section{Multistep Forming Process}

The aim of the present forming process is to reduce the relative bending radius from 1.5 in rotary bending to 0.56 in the target component. Two major methods are adopted to achieve this goal: further bending to decrease the bending radius and bulging to increase the outer diameter of the tube. Thus, a multistep partition-forming process is proposed in this study.

3.1. Process Solutions to Elbow Forming. In Figure 6, the geometry relationships of the prebent tube and target component are illustrated. They have a significant influence on the thickness distribution and the final part quality. Figure 6(a) demonstrates the most dangerous zones in the forming process. The pink area represents the target component, and the blue area is the tube blank. Section A is the center section in bending where the most thinning and thickening are located. Section B is the transition between the origin tube and the formed area, so the stress state here is similar to a uniaxial tension and is likely to fracture.

So, the prebent tube is divided into four subregions (see the cut view of section A in Figure 6(b)). Bent thinning 


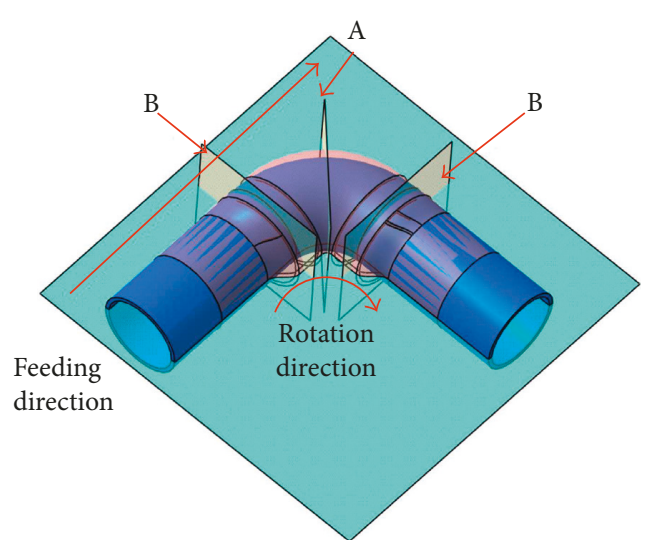

(a)

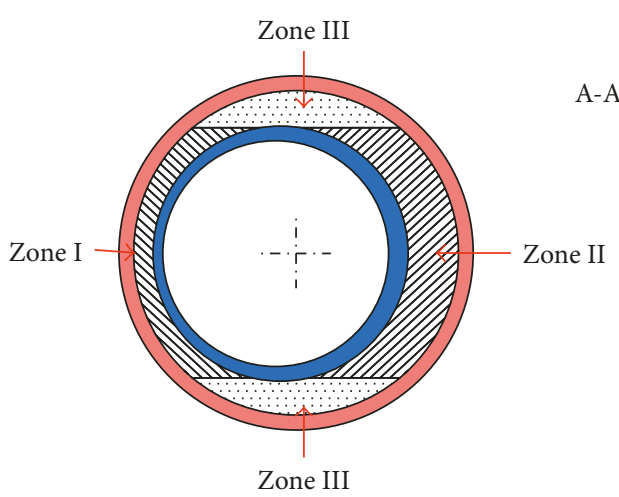

(b)

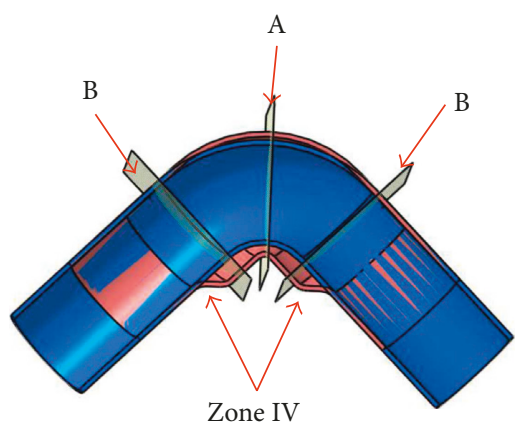

(c)

Figure 6: Geometry relationships of the prebent tube and target component. (a) Cross section indications. (b) Cross section A. (c) Cross section along the axial line.

region (I) is on the outside bend where the thickness is reduced by $15 \%$ through estimation. Cracking is highly probable to happen here when there is excess deformation induced by the hydroforming process.

Bent thickening region (II) is on the inside bend, where the thickness is increased by about $20 \%$. Here, there is a high risk of wrinkle due to the bending and the potential compression stresses under internal pressure mentioned previously. But it is interesting that there is enough material accumulated in this region after bending, leading to the possibility of avoiding feeding in bulging and prevention of the elbow from wrinkle.

The middle layer region (III), as the name suggests, is the middle layer area in the bending deforming region, and bending straight region (IV) (Figure 6(c)) is the inside region out of the deformed region. These two regions deform little in the bending process and almost retain almost full formability and retain full formability for next steps.

Above that, it indicates that the further thinning on the bent thinning region should be inhibited and more bulging deformation could be induced into the bent thickening area. In this way, the crack and wrinkle can be eliminated in the forming process. Thus, four steps are employed in this process: a rotary bending and three-step partition forming to control the tube deforming in sequence and make best use of the material. Figure 7 demonstrates the processes and main ideas in each step.
The first forming step (THF1) is a combination of crush bending and bulging to reduce the bending radius without springback.

The second step in the partition bulging process (THF2) aims to further increase the outer diameter by bulging the inside region of the tube. In the final hydroforming step (THF3), the middle layer and straight regions are dilated up and the whole part is calibrated to attach the target shape.

To enhance the formability of the material, in this study, the bright annealing process is also used after tube bending. 304 austenitic stainless steel, one of the most widely used materials, has good mechanical properties and corrosion resistance. However, the strain-induced martensitic transformation that occurs during the forming process will decrease the formability of the tubular material [14]. The yield strength $\sigma_{s}$ increases during the deformation. At the same time, the elongation decreases significantly. As the deformation is quite high in the bulging process, the risk of fracture will be increased. Bright annealing can refine the property of this austenitic stainless steel.

First, a series of simulations are performed using LSDYNA finite element code to predict the processes before experimentation. Considering the $2 \mathrm{~mm}$ thickness, the tube blank is meshed with shell elements in the Belytschko-Tsay type with a size of $3 \mathrm{~mm}$ and 5 integration points. Additionally, the tools are viewed as rigid bodies in simulations, and the friction coefficient between blank and tools is set to 0.125 . 


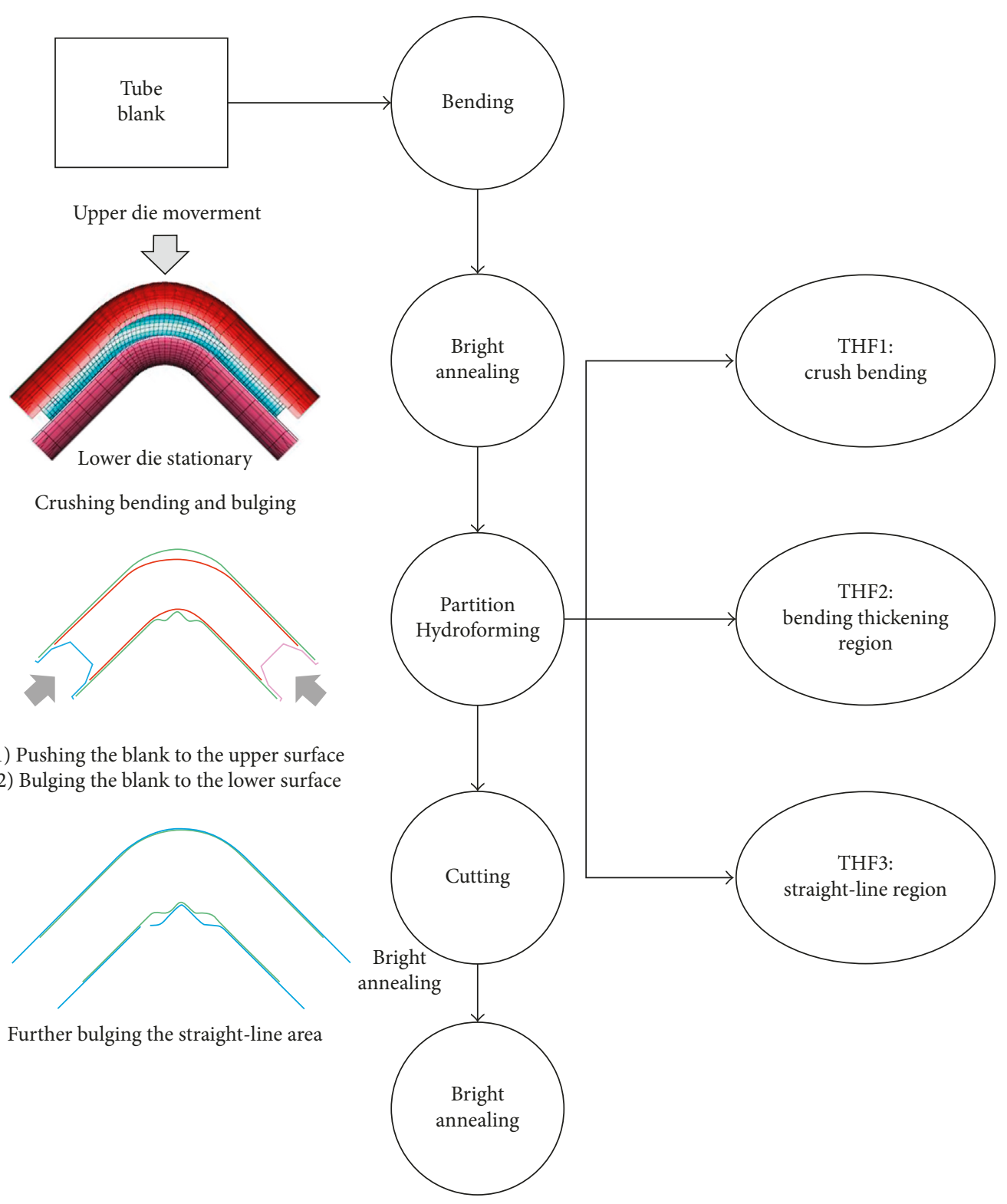

FIGURE 7: Flowchart of the partition-forming process.

At the end of an analysis, LS-DYNA code will write a "dynain" file. A "dynain" file contains a set of keyword data that can be inserted into an input deck to initialize deformation, shell thickness, and element history variables for the next analyze step. Otherwise, the annealing process can be simulated by removing the stress and strain information from the "dynain" file [15] which includes stresses, backstresses, plastic strains, and velocities.

3.2. Fine Design of the Partition-Forming Processes. In the bending process, the relative radius should be as small as possible while the thinning and thickening are considered. Although there are several types of bending methods that can be applied as preforming in the process, the NC rotary bending was selected for its stability and predictability of springback, as seen in Figure 8. The front of the blank is fixed in the cavity between the clamp die and bend die, and the middle section is bent by the rotation of the bend die. The rear goes forward with the push die and constrained by the pressure die and wiper die. In the inner cavity of the tube, there are mandrels and balls to prevent the tube from wrinkling or distorting.

Three major parameters need to be determined such as initial diameters of the blank $D_{0}$, bending radius $R$, and bending angle $\alpha$. In most tube hydroforming processes, the minimum outer diameter on the final parts can be taken as the initial diameters $D_{0}$ of blanks. In elbow forming, because of the limited relative bending radius, $D_{0}$ should be much smaller than usual. The deformation on the tube must be carefully controlled. To obtain a reasonable prebent tube, $D_{0}$ is selected as $42 \mathrm{~mm}$ which is a common dimension used in tube blanks to lower computational cost. $R$ is $63 \mathrm{~mm}$, so the relative bending radius is 1.5 , which is a commonly 


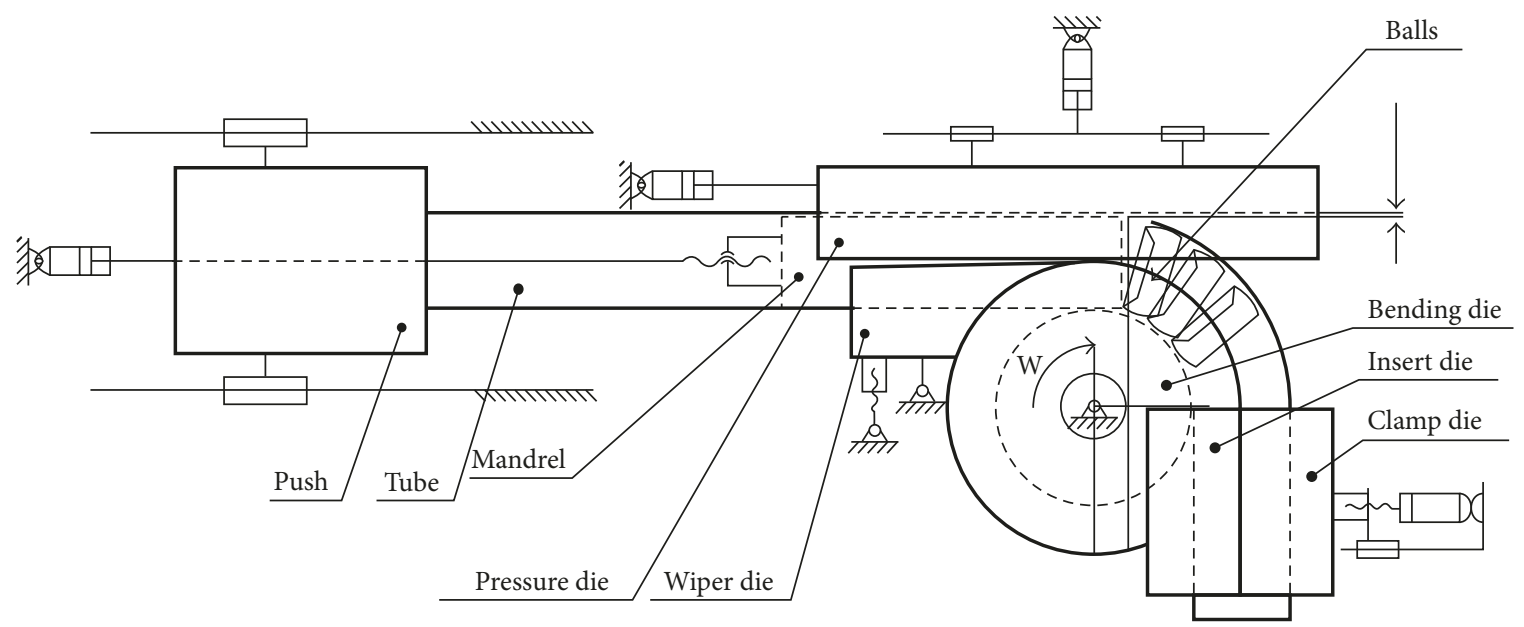

FIGURE 8: Schematics of the rotary bending process.

TABle 1: Dimensions of rotary bending tools ( $\mathrm{mm}$ ).

\begin{tabular}{lcccccccc}
\hline Tool & Insert die & Clamp die & Pressure die & Wiper die & Mandrel shaft & Balls & Ball interval & Ball width \\
\hline Length & 126 & 126 & 126 & 126 & 126 & 3 & 20 & 10 \\
Gap & 0.12 & 0.12 & 0.12 & 0.12 & 0.3 & 0.3 & 0.3 & 0.3 \\
\hline
\end{tabular}

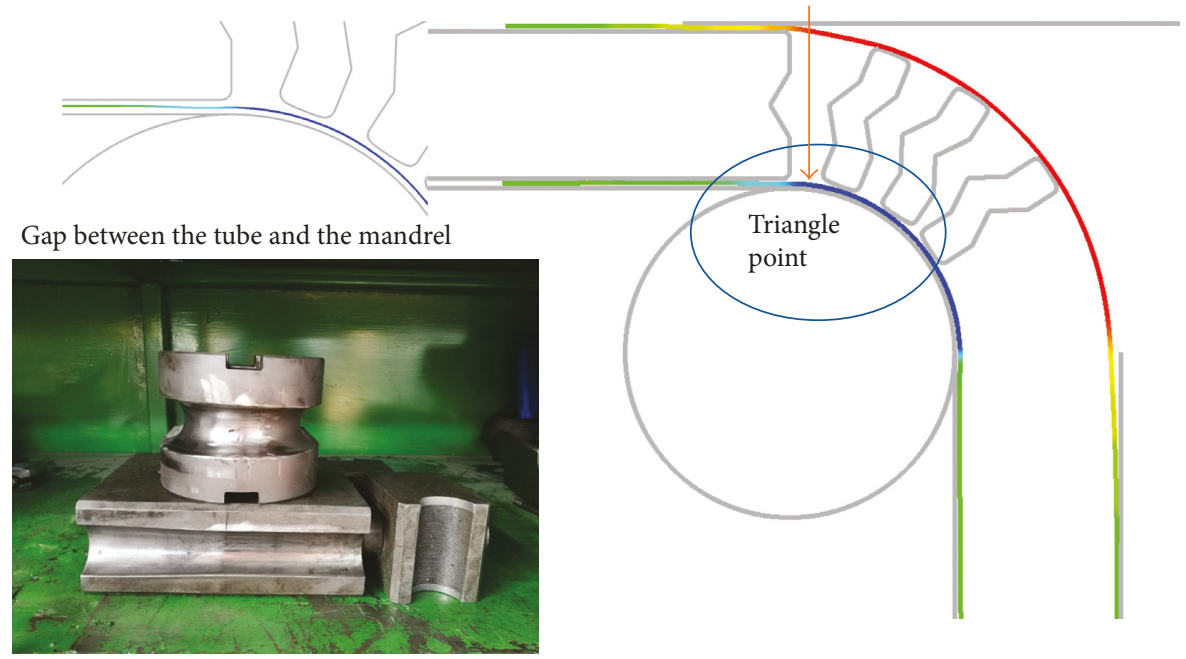

FIgURE 9: Thickness distribution after rotary bending.

acceptable value in rotary bending. Considering the general springback coefficients, the bending angle $\alpha$ is selected to be $92^{\circ}$.

In addition, there are several other parameters that affect the bending quality especially the wrinkle, such as the number of mandrel balls and the interval between the balls and ball width. The wrinkle on the thickening region can be divided into two sections: before and after the tangent point. The wrinkle before the tangent point is mainly caused by the compressive stresses during the bending, and the other is caused by the hindering effect of the balls on the blank movement. As a result, a smaller gap between the mandrel and blank is preferred, and a larger gap between balls and blanks is better. The gap here indicates the distance from the mandrel and ball's outer surfaces to the inner surface of the tube blank. The main dimensions of rotary bending tools are listed in Table 1. The thickness distribution in finite simulation can be seen in Figure 9. The minimum thickness is about $1.73 \mathrm{~mm}$ on the outside, and the maximum thickness is $2.37 \mathrm{~mm}$ on the inside. The corresponding thinning ratio is $13.33 \%$ and $-18.65 \%$, and there is no obvious wrinkle found after bending.

Then, a bright annealing is performed to improve the formability of the tube. It is heated gradually from room temperature to $1050^{\circ} \mathrm{C}$ in a protective atmosphere, held for 30 minutes, and then cooled down in air [9], as seen in 


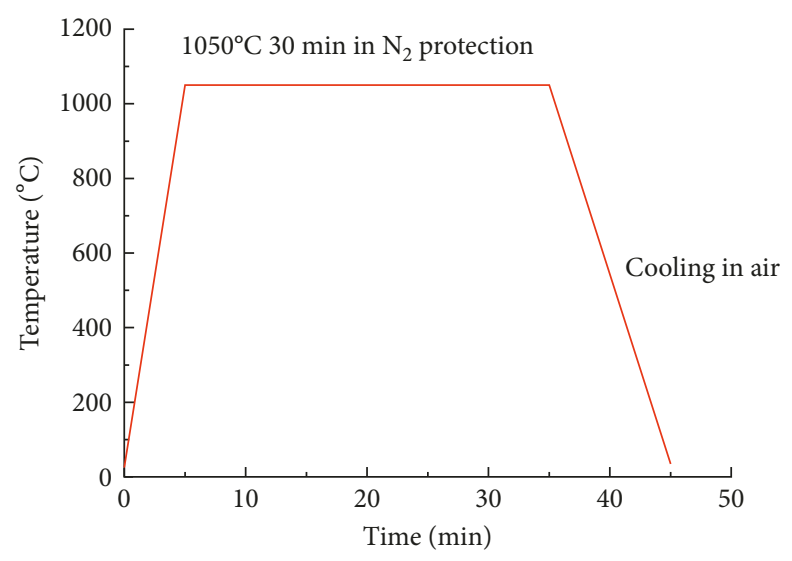

FIgURE 10: Temperature-time profile used for the BA process.

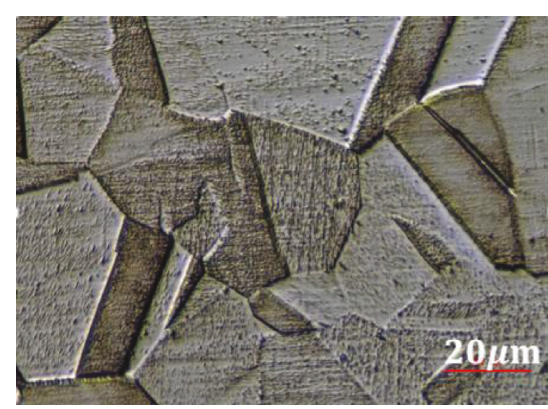

(a)

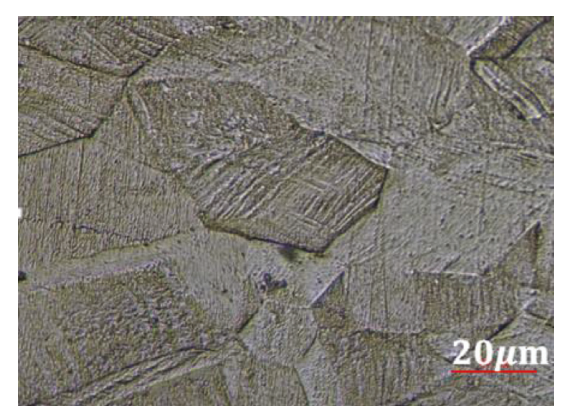

(b)

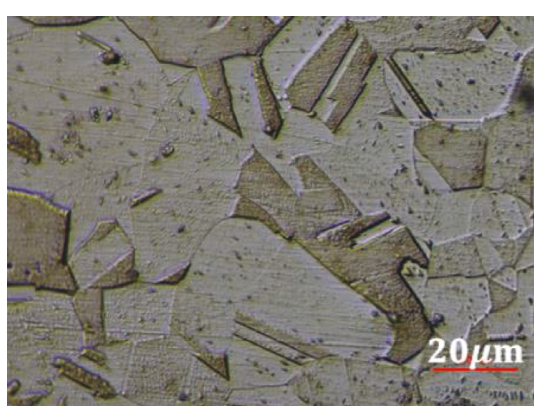

(c)

Figure 11: Crystalline phase (100x). (a) Before bending. (b) After bending. (c) After bright annealing.

Figure 10. Thus, the most optimal mechanical properties of the SS304 tube for the hydroforming process are provided. The yielding strength is about $170 \mathrm{MPa}$, and a total elongation of about $70 \%$ can be obtained. It is worth mentioning that the BA treatment introduces little changes in the bending angle but does not affect the bulging process.

The average grain size is estimated according to ASTM E112 [15] to verify the validity of using bright annealing through observation of the microstructure evolution, as seen in Figure 11. The martensitic fraction is measured using the grid method. The sample before bending is homogeneous austenite. The grains are moderate in size, and boundaries are mostly straight edges. No martensite is found here.

The grains are squashed after bending. Some austenite grains exhibit characteristics of slip lines, which are presumed to be martensite produced by deformation. Other grains retain the twin characteristics of austenite. The volume fraction of martensite is between $14 \%$ and $22 \%$, and the average grain size is about 6.50 .

The microstructure recovers, and an obvious recrystallization occurs during the bright annealing treatment. The martensite totally transforms back to austenite. Besides, the grains are with smaller size due to the heat temperature and holding time. The average grain size here is about 8.18.
After heat treatment, a three-step partition-forming process is employed. As mentioned above, THF1 is a combination of crush bending and bulging. Crushing operation is a common process within hydroforming during die closing employed to refine the thickness distribution and make additional deformations in the tubular part [5]. In this study, the closing movement of the upper die is in the prebending plane and the direction is the center line in prebending, so it can be deemed to be crush bending, as seen in Figure 12(a). To reduce springback [16], the internal pressure should be imposed subsequently to release residual stress on the tube.

The expansion ratio is limited to prevent the bent thinning region from serious thinning in this step. Meanwhile, since it is not necessary to feeding material into the deforming zone here, only the internal pressure needs to be considered in the loading path design. The maximum value $p$ can be expressed as

$$
p=\frac{2 t \sigma_{\mathrm{t}}}{D-t}
$$

where $\sigma_{\mathrm{t}}$ is the tensile strength of the material.

Figure 12(c) demonstrates the strain paths of these two regions of the tube in this step. In the crush-bending stage, 


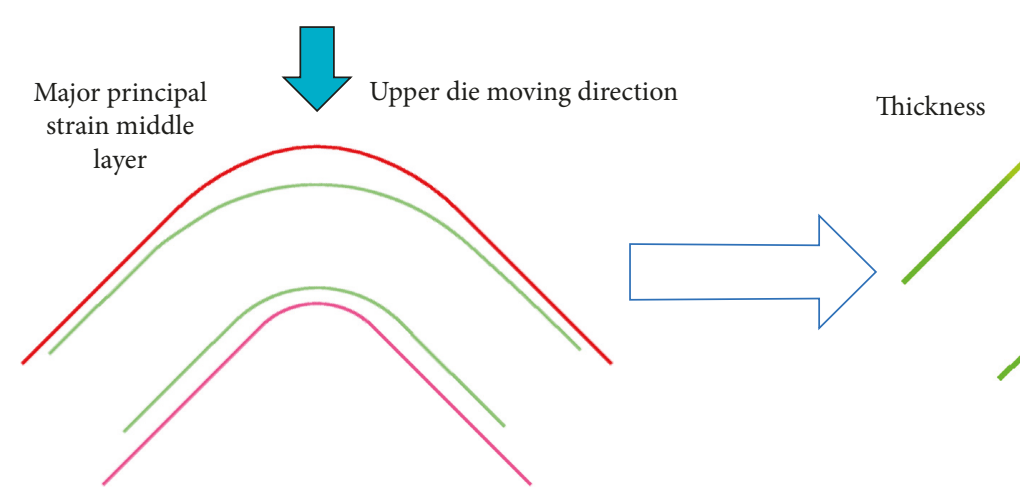

(a)

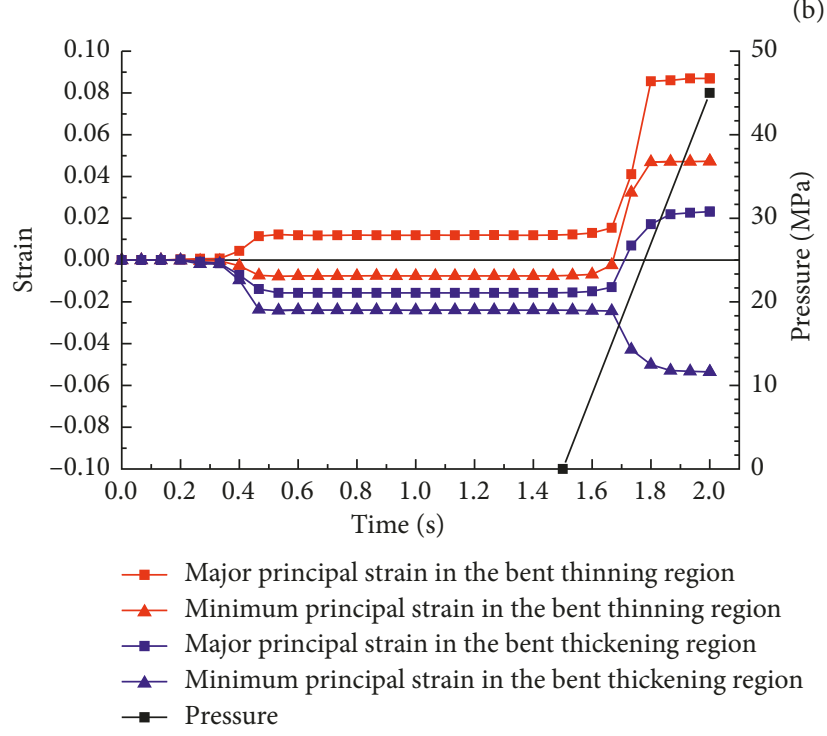

(c)

Figure 12: The first forming step: (a) die movement, (b) thickness distribution, and (c) strain paths of subregions I and II.

the bent thinning region is under a tensile-compress state and the thickness retains stability. The thickening region is under the compress-compress state, so the material flows in and cumulates here. In the bulging process, there is not obvious deformation until the internal pressure about $45 \mathrm{MPa}$. Then, the strain state of the thinning region becomes tensile-tensile, which leads to a large deformation, and the thickness decreases rapidly. The thickening region is under the tensile-compress state, and no more thickening occurs. The least thickness of this region is $1.52 \mathrm{~mm}$ with the thinning ratio less than $25 \%$, which is a quite ideal result, as seen in Figure 12(b). The largest thickness in the bent thickening region is $2.43 \mathrm{~mm}$ with the thinning ratio as $-21.5 \%$, and no wrinkle happens. In this step, the relative radius of the elbow decreases from 1.5 to about 1.2.

The second step in the partition bulging process (THF2) aims to further increase the outer diameter by bulging the bent thickening region to obtain a better thickness distribution. To achieve this goal, there is a sight pushing on both the ends that the thinning region to attach the die surface before the internal pressure is increasing, so friction between the tube and die can help to reduce the sustained thinning here, as shown in Figures 13(a) and 13(b). There are a small radius fillet to be formed in this step with the value of $4 \mathrm{~mm}$ on the thickening region and another two fillets with the value of $5 \mathrm{~mm}$ on the straight-line regions. In this condition, the maximum forming pressure is called calibration pressure $p_{\text {cal }}$. It can be given by the following formula:

$$
p_{\text {cal }}=\frac{2}{\sqrt{3}} \frac{t_{\mathrm{i}} \sigma_{\mathrm{t}}}{R_{\min }-t_{\mathrm{i}} / 2}
$$

where $R_{\min }$ is the minimum fillet radius for the target part.

It can be found that the minimum thickness of the bent thinning region is kept as $1.52 \mathrm{~mm}$, and the thickening region is further thickened slightly during pushing. Then, during the increasing of internal pressure, the thickening region starts deforming. The tube is stretched in hoop direction and shrinks in the axial direction, due to which the thickness in this area decreases. The area on the intersection of thickening and straight-line regions should be emphasized as it is the most thinning (MT) region on the tube. Meanwhile, this area needs to be formed into the fillets, as shown in Figure 13(c). The thickness here changes from $2.3 \mathrm{~mm}$ to $2.0 \mathrm{~mm}$ with the thinning ratio as $15 \%$. They have similar strain paths to the thickening region here, as shown in Figure 13(d). MT begins to deform earlier, and the effective strain is smaller. It is because that the initial thickness 


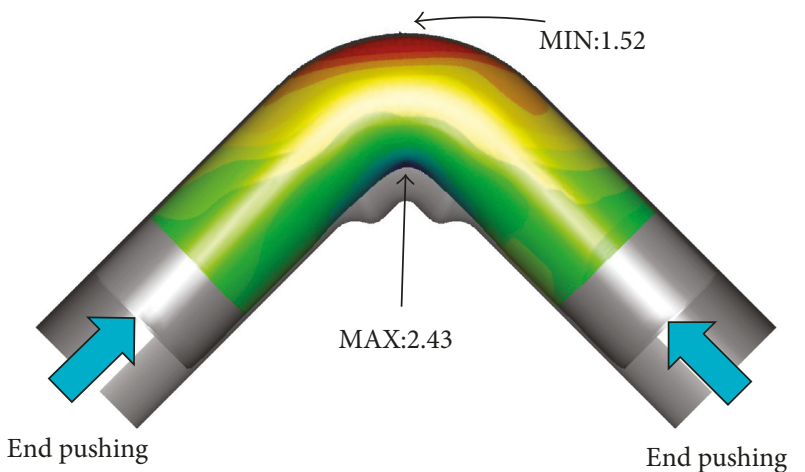

(a)

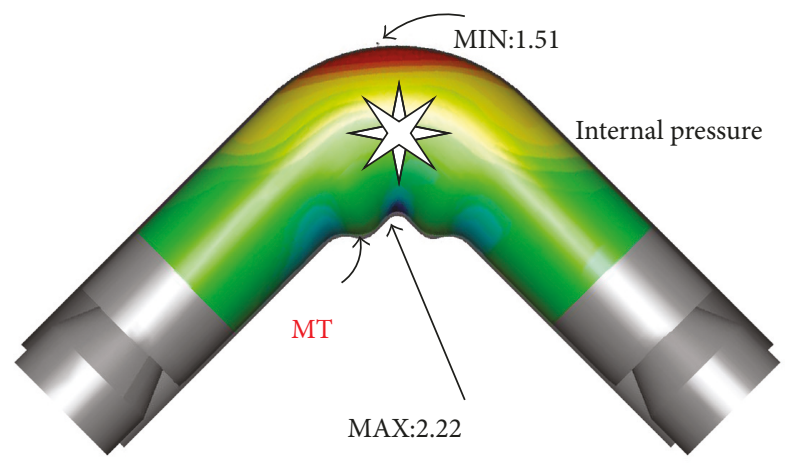

(c)

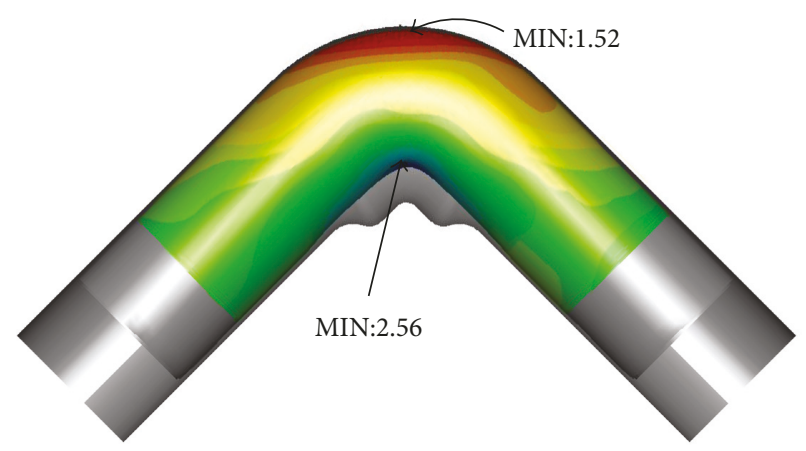

(b)

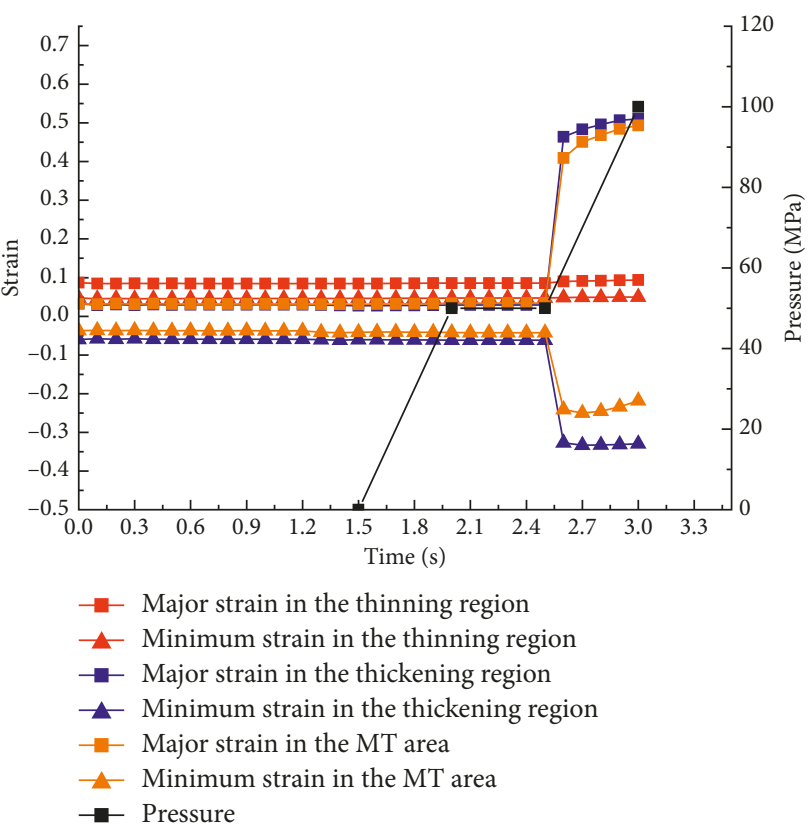

(d)

FIgURE 13: The second forming step: (a) pushing starts, (b) pushing ends, (c) bulging, and (d) strain paths.

here is lower and MT areas first attach the die surface. Additionally, the strain paths of the thinning region are still stable in bulging. It indicates that although a tensioncompression deformation occurs on the thickening region, there is no more material accumulation.

In the third bulging step, the tube needs to be further expanded, while the fillet needs to be further calibrated. Similar to the last step, a sight prepushing is adopted to prevent thinning region deforming, as seen in Figures 14(a) and $14(\mathrm{~b})$. Then, the internal pressure raises up to $160 \mathrm{MPa}$ since the minimum fillet radius is $3 \mathrm{~mm}$. The middle layer region dilates up along with further deforming on the thickening region so that section A-A transforms from an ellipse into a circle with the diameter of $50 \mathrm{~mm}$, as shown in Figure 14(c). As there is sufficient material formability here, no risk of crack exists. The strain path here is more likely in an axial tension state. In addition, the straight-line region and MT area are expanded in similar tension-compression strain states, but the magnitude of straight-line region is much higher, as demonstrated in Figure 14(d). It can also be seen that the deformation of the thinning region can be ignored and MT area continues to deform in this step but much lower than the last step. It indicates that the strategy of partition forming can effectively control the deformation on the tube in the process.

The springback of the final bulging process is shown in Figure 15. Single point constraint is applied on one side of the end in simulation. The most springback displacement is less than $0.35 \mathrm{~mm}$ on the other end which is ignorable in the forming process. Finally, end cutting and, at this point, the ultrasmall bending radius elbow part are obtained.

\section{Results and Discussion}

In this study, a multistep forming process is employed to obtain an ultrasmall bending radius elbow. Each of these steps aims to make a special region of the tube deformed to make the thickness distribution uniform. As shown in Figure 14, the deformation in bent thinning regions is quite low, and the bent thickening regions reduce their thickness sequentially 


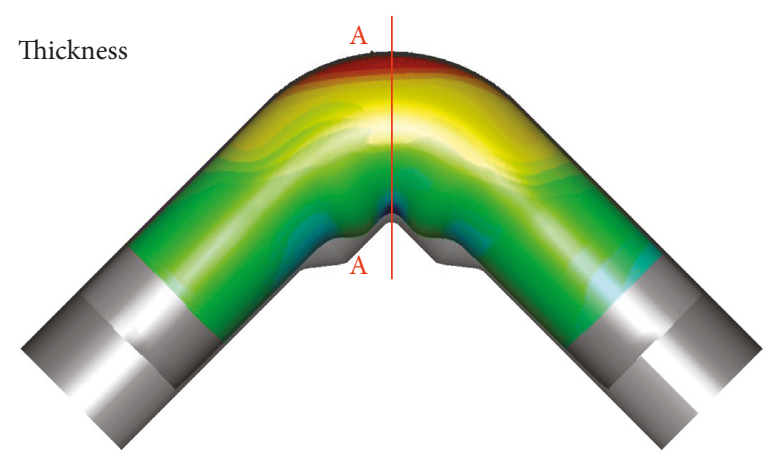

(a)

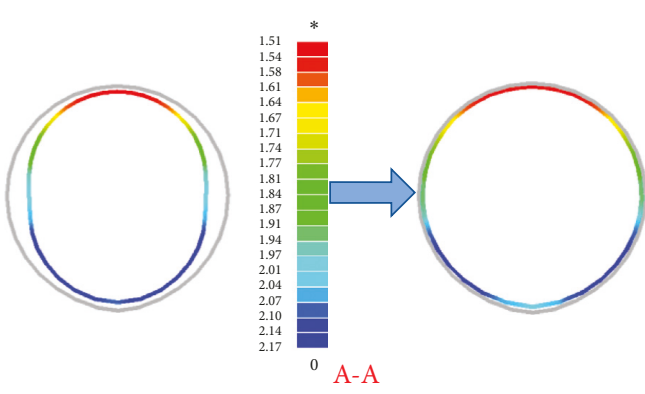

(c)

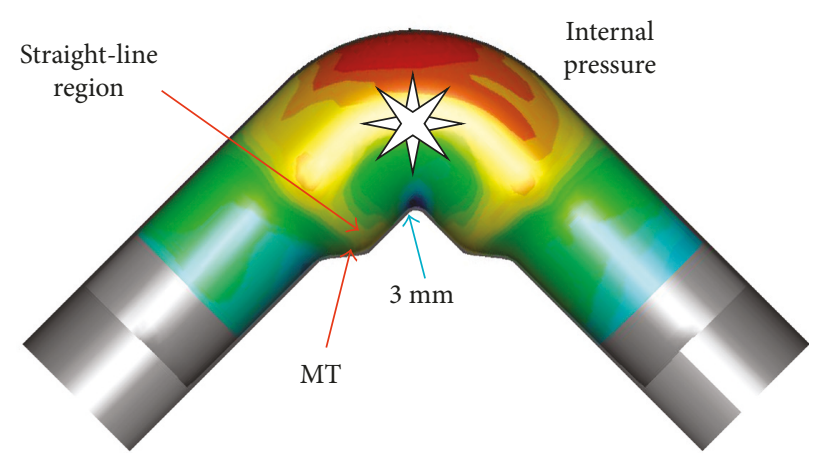

(b)
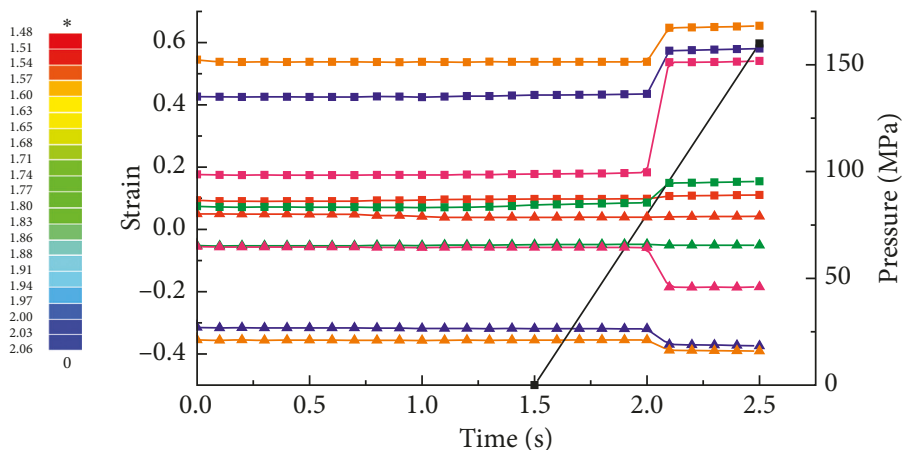

$\rightarrow-$ Major strain in the thinning region

- Minimum strain in the thinning region

^ Major strain in the thickening region

$\rightarrow$ Minimum strain in the thickening region

$\rightarrow$ Major strain in the middle layer region

- Minimum strain in the middle layer region

$\rightarrow-$ Major strain in the straight-line region

- Minimum strain in the straight-line region

$\rightarrow$ Major strain in the MT area

- Minimum strain in the sub-MT area

$\rightarrow$ Pressure

FIgURE 14: The final forming step: (a) part location, (b) bulging, (c) cross-section deformation, and (d) strain paths.
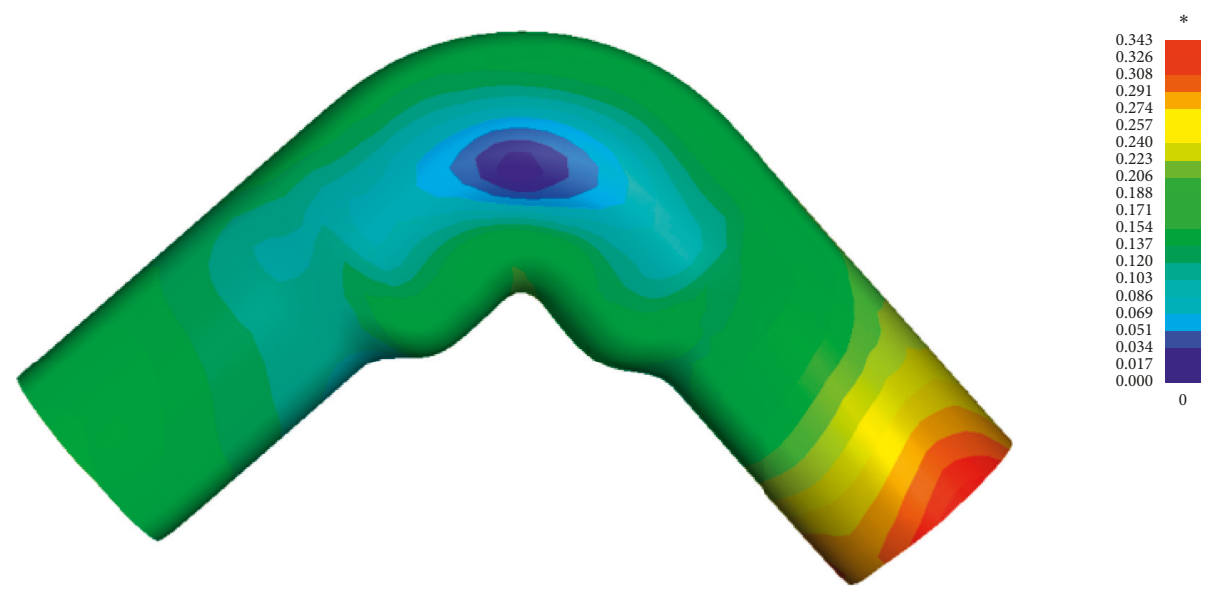

Figure 15: Springback in the final forming step. 


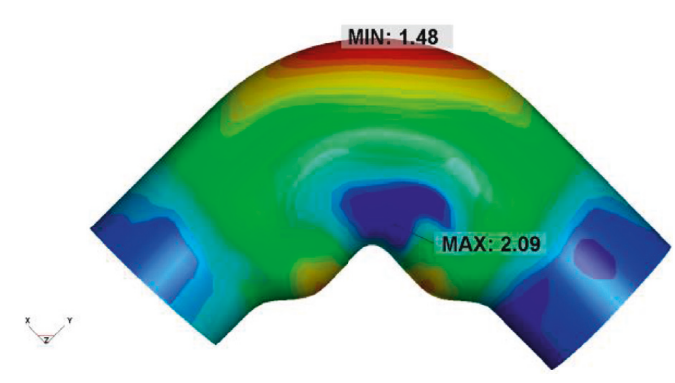

(a)
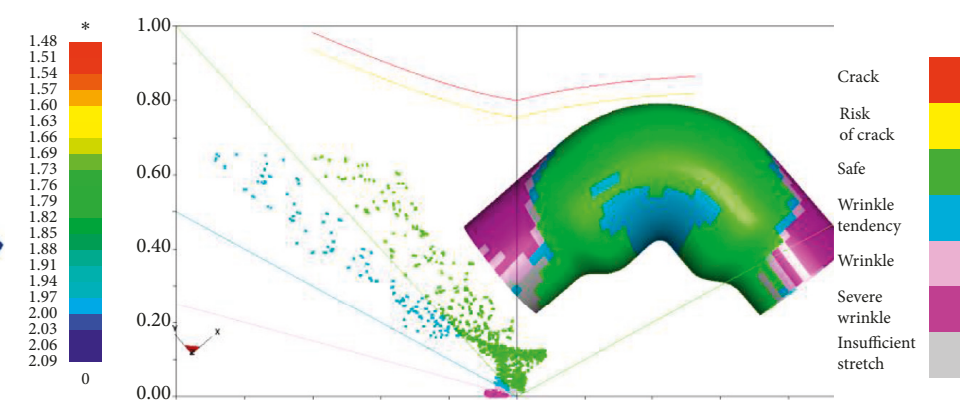

(b)

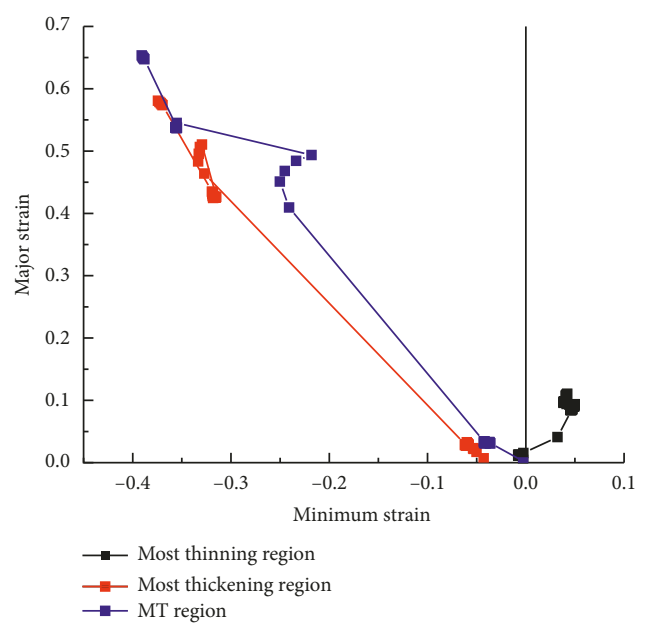

(c)

Figure 16: Quality of the target component. (a) Thickness distribution. (b) Forming limit diagram. (c) Strain paths of crucial regions.

chiming in the partition-forming process. The final formed component is shown in Figure 16. There are three thinning areas which are present in the bent thinning region and straight-line region and one thickening area which appears on the bent thickening region. The least thickness is $1.48 \mathrm{~mm}$ with the thinning ratio of $26 \%$, which is a reasonable result compared to the design requirement. The most thickness is only $2.09 \mathrm{~mm}$, which reduces during the hydroforming processes after bending.

Figure 16(b) instructs the forming limit diagram of the hydroforming process. Although the strain path of the tube is not linear in different steps, it is believable that the material has a large safe margin to the limit lines. The strain paths of most bending thinning, thickening, and MT regions are shown in Figure 16(c). No crack nor wrinkle will occur in the elbow component. This is due to the reasonable controlling of the deformation extent and order by the partitionforming process. In Figure 17, the deformation processes of cross sections A and B in Figure 6, which are the most typical features on the component, are clearly demonstrated. Section $\mathrm{A}$ has the most thinning and thickening area after bending. Bent thinning, thickening, and middle layer regions are formed in a controllable sequence in steps using the boundary conditions of die design. As the straight-line region rarely changed in the bending process and is located out of the wrinkle zone, the major forming process of this region is in the final calibrating step during the increase of internal pressure. It is worth mentioning that because there is no material feeding during the bulging processes, design of the loading path can be sufficiently simplified.

The process design then is validated by experiments, as shown in Figures 18(b) and 18(c). There is no defect found on the component. The crystalline phase experiment is also implemented after the final forming process. The martensite content is about $30 \%$. Finally, an extra bright annealing process is used to release the stress and strain on the formed component to restore the microstructure of the material. The typical austenite structure with small grain size, planar boundary, and twins is found in Figure 18(d).

\section{Conclusion}

In this study, both numerical and experimental investigations are performed on a multistep tube hydroforming process considering the rotary bending, heat treatment, and a partition-forming method to obtain an ultrasmall bending radius elbow component.

Because there is a phase transformation from austenite to martensite at the curve zones during the rotary bending process, bright annealing must be provided before bulging to improve the formability.

As the foundation of the process design, the reason of wrinkle that could happen in forming is analyzed. Due to the 


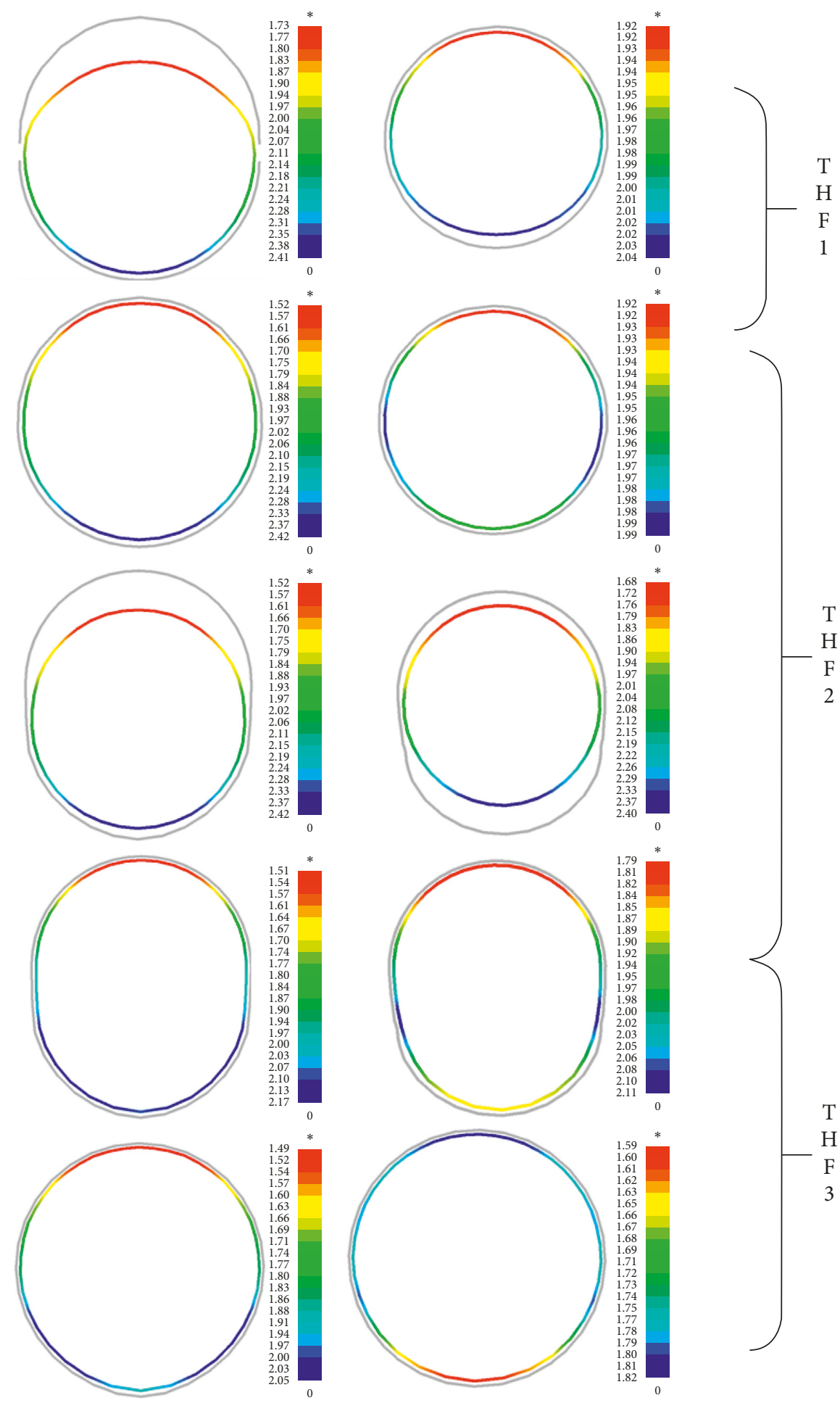

(a)

(b)

FIgURE 17: Deformation processes in (a) section A and (b) section B.

analysis, it is found that the material feeding during bulging should be abolished in small radius elbow forming. The loading paths can be simplified into achieving the highest value of internal pressure in each step, which shows excellent agreement between the experiments and simulations.
Partition-forming process is introduced to take full advantage of the material features after bending. The results show that the considerable thickness variations at the curve zone can help to achieve a better thickness distribution after hydroforming. The process of partition forming utilizes the 


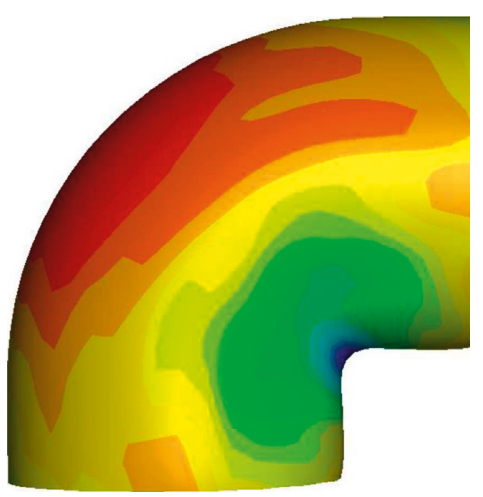

(a)

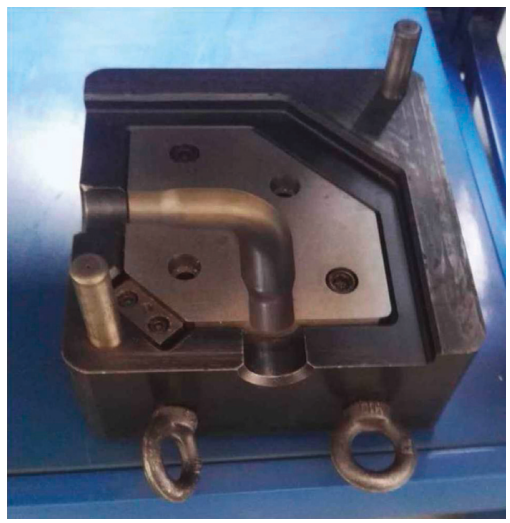

(c)

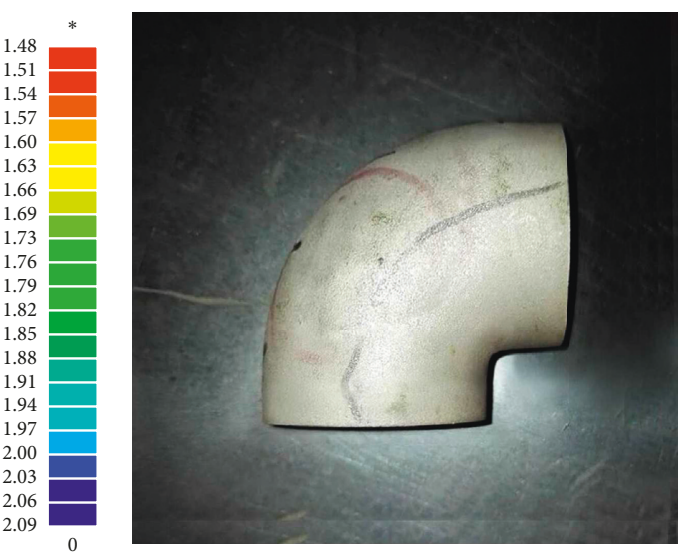

(b)

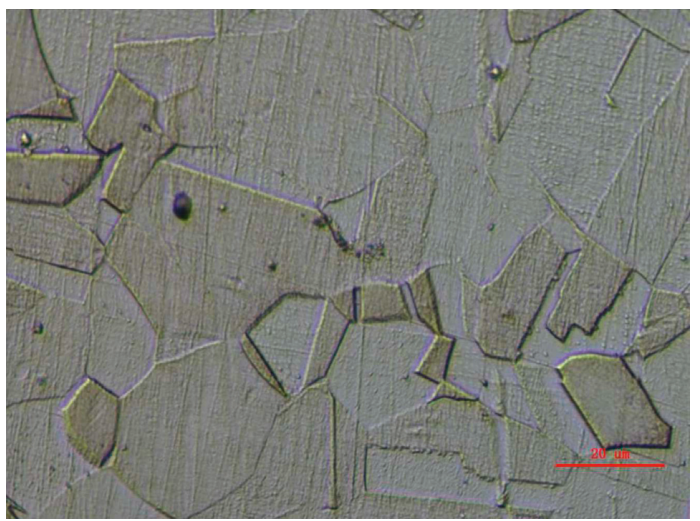

(d)

Figure 18: Ultrasmall bending radius elbow. (a) Trimmed simulation component. (b) Trimmed experimental component. (c) Tool set for the final forming step. (d) Microstructure after final annealing.

boundary conditions provided by the die surface to efficiently control the deformation path of each subregion for hydroforming a qualified component without crack and wrinkle defects.

\section{Conflicts of Interest}

The authors declare that there are no conflicts of interest regarding the publication of this paper.

\section{References}

[1] J. Chattopadhyay, D. K. Nathani, B. K. Dutta, and H. S. Kushwaha, "Closed-form collapse moment equations of elbows under combined internal pressure and in-plane bending moment," Journal of Pressure Vessel Technology, vol. 122, no. 4, pp. 431-436, 2000.

[2] H. Li, H. Yang, J. Yan, and M. Zhan, "Numerical study on deformation behaviors of thin-walled tube NC bending with large diameter and small bending radius," Computational Materials Science, vol. 45, no. 4, pp. 921-934, 2009.

[3] Z. Hu and J. Q. Li, "Computer simulation of pipe-bending processes with small bending radius using local induction heating," Journal of Materials Processing Technology, vol. 91, no. 1-3, pp. 75-79, 1999.
[4] L. Lian, J. F. Wu, B. Li, and N. T. Zhou, "Simulation of shaping large-size thin-walled elbow for ITER-PF feeder system," Hejubian Yu Dengliziti Wuli, vol. 34, no. 3, pp. 247-251, 2014.

[5] M. Koç, Hydroforming for Advanced Manufacturing, Woodhead Publishing, Cambridge, UK, 2008.

[6] S. Yuan, B. Teng, and Z. R. Wang, "A new hydroforming process for large elbow pipes," Journal of Materials Processing Technology, vol. 117, no. 1-2, pp. 28-31, 2001.

[7] S.-G. Shr, Bending of Tubes for Hydroforming: A State-of-the-Art Review and Analysis, The Ohio State University, Columbus, OH, USA, 1998.

[8] D. Kong, L. Lang, S. Ruan, Z. Sun, C. Zhang et al., "A novel hydroforming approach in manufacturing thin-walled elbow parts with small bending radius," International Journal of Advanced Manufacturing Technology, vol. 90, no. 5-8, pp. 1579-1591, 2017.

[9] P. Thanakijkasem, V. Uthaisangsuk, A. Pattarangkun, and S. Mahabunphachai, "Effect of bright annealing on stainless steel 304 formability in tube hydroforming," International Journal of Advanced Manufacturing Technology, vol. 73, no. 9-12, pp. 1341-1349, 2014.

[10] Y. Ma, Y. Xu, S. Zhang et al., "The effect of tube bending, heat treatment and loading paths on process responses of hydroforming for automobile intercooler pipe: numerical and experimental investigations," International Journal of 
Advanced Manufacturing Technology, vol. 91, no. 5-8, pp. 2369-2381, 2017.

[11] H. An, D. Green, J. Johrendt, and L. Smith, "Multi-objective optimization of loading path design in multi-stage tube forming using MOGA," International Journal of Material Forming, vol. 6, no. 1, pp. 125-135, 2013.

[12] Y.-L. Ge, X.-X. Li, L.-H. Lang, and S.-W. Ruan, "Optimized design of tube hydroforming loading path using multiobjective differential evolution," International Journal of Advanced Manufacturing Technology, vol. 88, no. 1-4, pp. 837-846, 2017.

[13] S. Yuan, Modern Hydroforming Technology, National Defence Industry Press, Beijing, China, 2009.

[14] Z.-Y. Xue, S. Zhou, and X.-C. Wei, "Influence of pretransformed martensite on work-hardening behavior of SUS 304 metastable austenitic stainless steel," Journal of Iron and Steel Research, International, vol. 17, no. 3, pp. 51-55, 2010.

[15] ASTM, Standard Test Methods for Determining Average Grain Size, ASTM International, West Conshohocken, PA, USA, 2013.

[16] C.-P. Jiang and C.-C. Chen, "Grain size effect on the springback behavior of the microtube in the press bending process," Materials and Manufacturing Processes, vol. 27, no. 5, pp. 512-518, 2012. 


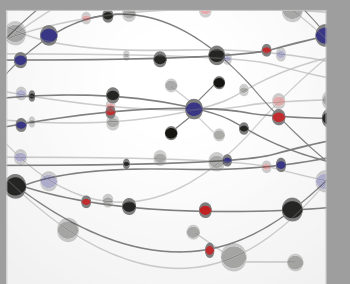

The Scientific World Journal
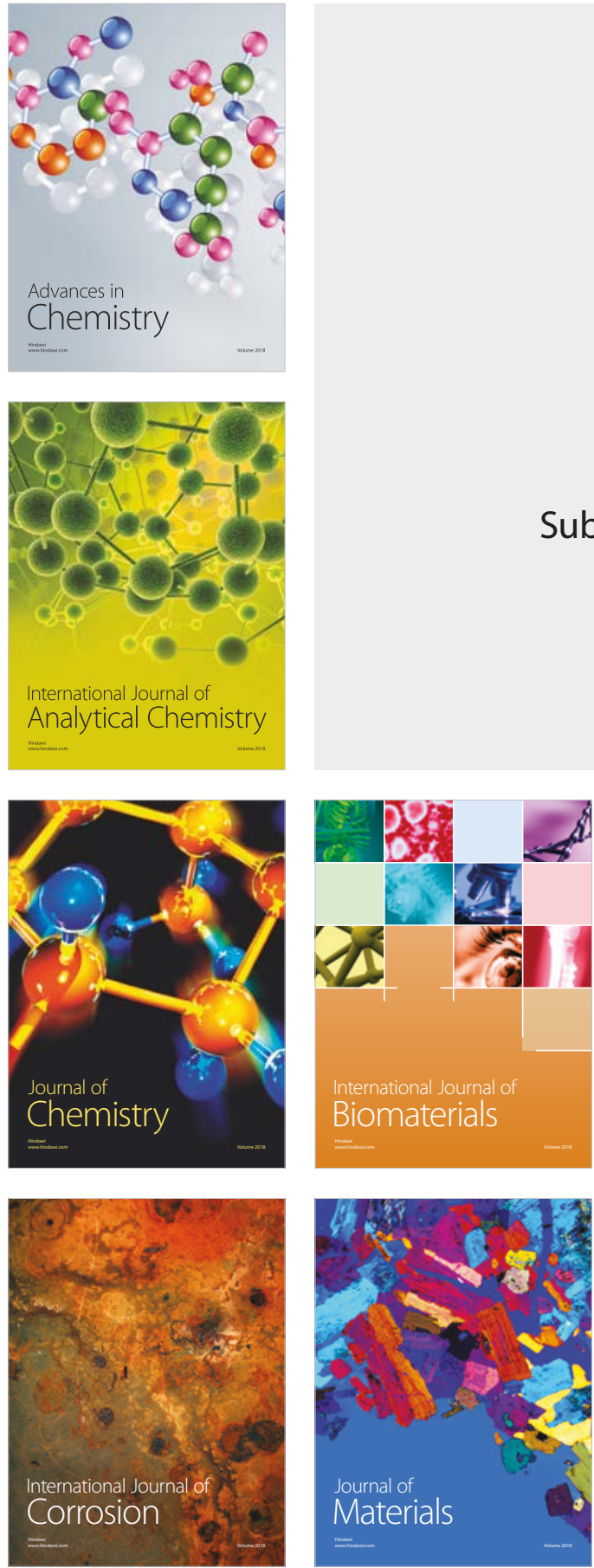

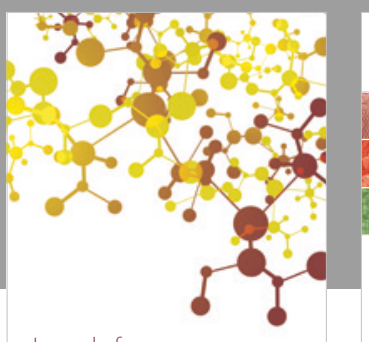

Journal of

Applied Chemistry
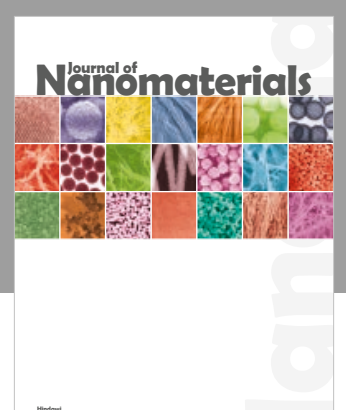

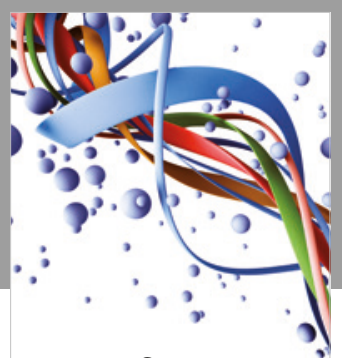

Scientifica

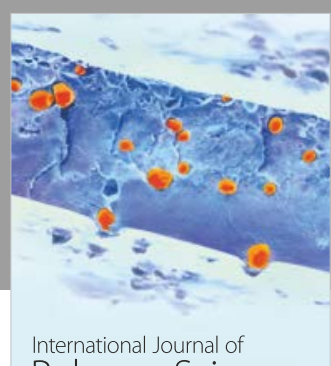

Polymer Science

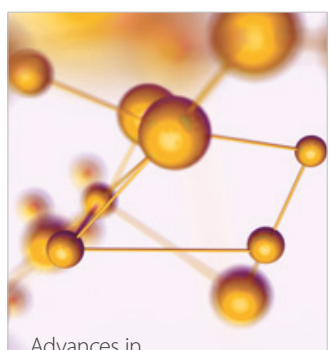

Physical Chemistry
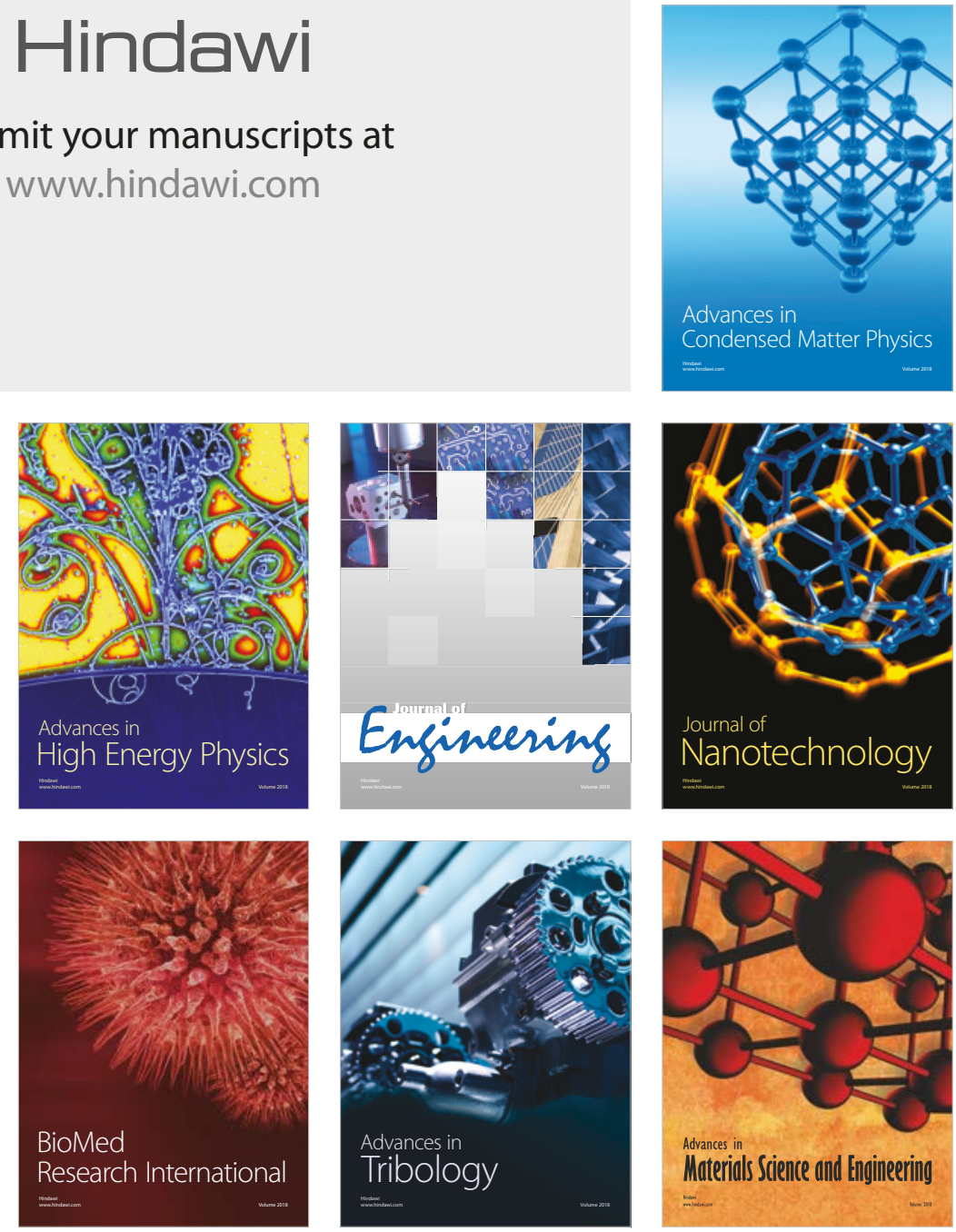